\title{
Determinants of postnatal maternity care service utilization in rural Belgaum of Karnataka, India: A community based cross-sectional study
}

\section{Dillee Prasad Paudel, Baburao Nilgar', Manisha Bhandankar ${ }^{2}$}

Departments of Public Health, ${ }^{1}$ Department of Obstetrics and Gynecology, ${ }^{2}$ Department of Pediatrics, Jawaharlal Nehru Medical College, Karnataka Lingayat Education University,

Belgaum, Karnataka, India

Address for correspondence:

Dr. Dillee Prasad Paudel,

Department of Public Health, Jawaharlal Nehru Medical College,

Karnataka Lingayat Education

University, Nehru Nagar,

Belgaum - 590010

Karnataka, India

E-mail: paudeldp@gmail.com

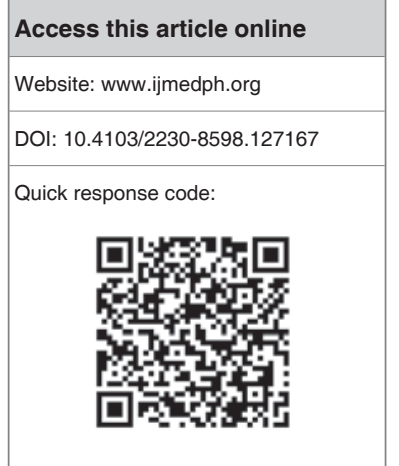

Background: The postnatal period is critical to the health and survival of a mother and her newborn. Lack of care in this period may result in death or disability as well as missed opportunities to promote healthy behaviors, affecting women and newborn children. Hence, the study was carried out to explore determinants of postnatal maternity service utilization in the rural area of Belgaum. Materials and Methods: Community based cross-sectional study was carried out from August 2012 to January 2013 in rural Belgaum. Total 630 mothers with less than 1 year child were interviewed using pretested questionnaire with her written consent. Analysis was done in Statistical Package for Social Sciences (SPSS) version 20 applying appropriate statistics. Results were presented in tabular and narrative forms. Results: Among 630 mothers, $54.6 \%$ were $20-24$ years of age, $61.6 \%$ were having secondary level of education, $89.8 \%$ house wives and $91.6 \%$ Hindus. About $69.7 \%$ were from joint family with low economic status. Regarding postnatal service use; $79.0 \%$ use properly. Almost; three-fifth met with nurse/health workers at least three times, four-fifth got advice about breast/nipple care, $92.5 \%$ about breast-feeding, $67.9 \%$ about post-natal exercise, $89.0 \%$ on nutrition education, and $85 \%$ got the advice of uterus care. About $29.8 \%$ perceived some health problems. Education, income, awareness, and delivery places were found most significant determinants $(P<0.01)$ of postnatal services use. Conclusion: More than three quarters of mothers had used the proper postnatal maternity services. Education, family income, awareness, and delivery place were found as most significant factors. Sustainable maternal and child healthcare $(\mathrm{MCH})$ programs and awareness will support to achieve furthermore better results.

Key words: Determinants, health service utilization, maternity services, postnatal care

\section{INTRODUCTION}

The postnatal period-defined here as the first six weeks after birth — is critical to the health and survival of a mothers and her newborn. The most vulnerable time for both is during the hours and days after birth. Lack of care in this time period may result in death or disability as well as missed opportunities to promote healthy behaviors, affecting women, newborns, and children.

Globally, estimated 1.5 billion women were of childbearing age (15-45-year-old) in 2011. A total of 210 million become pregnant every year; of which 13.33\% (28 million) covered by developed countries and remaining huge portion $(86.66 \%)$ is in developing world including India. ${ }^{[1,2]}$ Over half a million women encounter complications due to childbirth annually and many die. Almost 40\% of women experience complications after delivery and an estimated $15 \%$ of these women develop potentially life-threatening problems. ${ }^{[3,4]}$ Most of the maternal problems and deaths can be prevented or reduced if women had access to, or visited maternal health services during pregnancy, childbirth, and the postnatal period. ${ }^{[3,5]}$

Maternal and child healthcare $(\mathrm{MCH})$ is a major component of primary healthcare (PHC). ${ }^{[6]}$ Mother and child health is the first priority based program of India. First National Health Policy 1983, Population Policy 2000, Revised Health Policy 2002, and National Rural Health Mission (NRHM) 2005 gave emphasis on improvement of the health status of mothers and their children in rural areas. ${ }^{[7]}$ 
Postnatal care (PNC) refers to the assistance given to a mother and the baby for a period of six weeks from the time of delivery. Postnatal services are primarily comprised of physical examination, immunization, health education, and family planning services. Many women have not received these essential healthcare services yet though they need these services after delivery. Similarly the Millennium Development Goals 5 focused to improve maternal health (MDG 5 WHO), with targets to reduce maternal mortality by three quarters between 1990 and 2015, and to achieve universal access to reproductive health by $2015 .{ }^{[8]}$ To achieve this goal, the rural population need to be giving more scope. Utilization of postnatal health services can be affected by multitude of factors including accessibility, availability, quality of care as well as personal attitudes and socioeconomic characteristics. Hence, the study was carried out to explore health service utility pattern of mother during postnatal period and possible influencing factors in the rural area of Belgaum district.

\section{MATERIALS AND METHODS}

A community-based, cross-sectional study was carried out from August 2012 to January 2013 in the rural area of Belgaum district, Karnataka, India. Altogether 630 mothers with an infant were selected as study participants. Statistical formula; $N=Z^{2} \mathrm{pq} / \mathrm{d}^{2}$ was used to calculate the study sample with considering 1.5 design effect, $10 \%$ nonresponse rate, and 5\% allowable error. Two stages 30 clustered sampling technique was used. At first stage, Belgaum Taluk was selected from 10 Taluks of Belgaum district. There were 12 PHCs in rural area of Belgaum Taluk. Five PHC areas were selected randomly from these $12 \mathrm{PHCs}$ as study site. For selecting villages, all subcenter (SC) villages of each $\mathrm{PHC}$ and villages having no health institution (neither PHC nor SC) were listed separately. From each PHC area, the PHC village was selected. Further, two SC villages and three villages having not any health institution from each SC area were selected randomly. Thus, the study covered 30 villages as clusters. In second stage, three random points were identified in each selected cluster to cover all areas of the village. Then, 21 samples (seven from each point of each village) were taken from each cluster. Hence, all total 630 study participants were covered. Data were collected by interview using pretested structured questionnaire. Voluntary written consent was taken before starting the study. Data accuracy and reliability was mantained by double entry process and analyzed using Statistical Package for Social Sciences (SPSS, version 20). Percentage, means, standard deviation (SD), and odds ratio (OR) were calculated with applying logistic regression model. The criterion for statistical significance was set at the value of $P<0.05$. The analyzed data were disseminated in tables, graphs/charts, and narrative form as per necessity.

\section{RESULTS}

\section{Demographic finding of the study}

All together 630 mothers (mean age \pm SD: $24.14 \pm 3.21$ years) were participated in the study. About $54.6 \%$ of the participants were 20-24 years of age, whereas 37.1\% were 25-29 years. More than three-fifth $(61.6 \%)$ of the participants had secondary level of education followed by primary level $(18.7 \%)$ and pre-university college (PUC; 9.4\%). Almost $89.8 \%$ of the participants were house wife and most of them (91.6\%) were Hindus followed by Muslim (7.5\%). More than three quarter $(78.3 \%)$ did nonconsanguineous married. About $69.7 \%$ were from joint family having the low class $(<3,000$ Indian rupees (IRs)/month) economic status. Nearly half $(49.8 \%)$ of the participants' husband were of secondary level education followed by primary level $(22.9 \%)$. About $45.6 \%$ of the participant's husbands were labors and very rare $(0.5 \%)$ were unemployed [Table 1 ].

\section{Postnatal service utility pattern}

Among 630 postpartum mothers participated in the study, $79.0 \%$ had used the postnatal services properly. Study showed, about $89 \%$ took iron and folic acid (IFA) tablet with meeting to nurses/health workers. More than three-fifth $(6.3 \%)$ of the participants met with nurse/health workers at least 3 times during postnatal period, but only one quarter of them took Vitamin 'A' capsule. Nearly four-fifth $(79.7 \%)$ got the advice related to care of breast and nipple. Almost $92.5 \%$ got the advice of art of caring the breast, $67.9 \%$ got the advice related to postnatal exercise and $89.0 \%$ got the nutrition education. About $71.1 \%$ got the advice of family planning and $32.4 \%$ of them were using any form of the contraceptives. About $29.8 \%$ of the women faced any type of health problem during their postnatal and later period. The common health problems perceived by them were puerperal sepsis with fever (35.1\%), uterus prolapsed with backache and abdominal pain $(27.1 \%)$, weakness $(14.4 \%)$, mastitis $(10.6 \%)$, vaginal bleeding with pain (7.4\%), and lower abdominal pain (5.3\%). About $46.8 \%$ of suffered women took medicine with the advice of nurses and health workers and $16.4 \%$ did home treatment without consulting any health workers, while $12.3 \%$ did not do anything. Most of the participants $(84.9 \%)$ got the advice for caring of uterus from nurses/health workers either they were suffered by uterus prolapsed or not [Table 2].

\section{Factors affecting post natal care service utilization pattern}

Postnatal services soon after the delivery to 42 days are particularly important to reduce the maternal and neonatal deaths. It can be affected by several factors. Education of the mother, family income, types and size of family, occupation of husband, level of knowledge on PNC, history of previous neonatal death, health service used by mothers during antenatal period and place of delivery were revealed to be significant factors $(P<0.05)$ determining to use PNC services [Table 3].

It also confirmed that the level of awareness on PNC $(P=0.002)$ and education of the mother $(P=0.02)$ were important contributing factors of PNC utilization. Educated women were double folds (95\% confidence interval (CI): 1.24-4.75) more likely to receive service than those who had no education, and women who were highly aware were 2.54 times (95\% CI: 1.133-5.904) more likely to 


\begin{tabular}{|c|c|c|}
\hline Characteristics & Frequency & Percentage \\
\hline \multicolumn{3}{|c|}{ Age of the respondent (in year) } \\
\hline$\leq 19$ & 12 & 1.9 \\
\hline $20-24$ & 344 & 54.6 \\
\hline $25-29$ & 234 & 37.1 \\
\hline $30-34$ & 32 & 5.1 \\
\hline$\geq 35$ & 8 & 1.3 \\
\hline \multicolumn{3}{|c|}{ (Mean age $\pm S D: 24.14 \pm 3.21$ years) } \\
\hline \multicolumn{3}{|c|}{ Educational status of respondent } \\
\hline Illiterate & 40 & 6.3 \\
\hline Primary level & 116 & 18.4 \\
\hline Secondary level & 388 & 61.6 \\
\hline PUC & 59 & 9.4 \\
\hline University degree & 27 & 4.3 \\
\hline \multicolumn{3}{|c|}{ Occupation of the respondent } \\
\hline House wife & 566 & 89.8 \\
\hline Farming & 23 & 3.7 \\
\hline Government service & 8 & 1.3 \\
\hline Private service & 5 & 0.8 \\
\hline Business & 4 & 0.6 \\
\hline Labor & 22 & 3.5 \\
\hline Other & 2 & 0.3 \\
\hline \multicolumn{3}{|l|}{ Religion } \\
\hline Hindu & 577 & 91.6 \\
\hline Muslim & 47 & 7.5 \\
\hline Jain & 3 & 0.5 \\
\hline Christian & 3 & 0.5 \\
\hline \multicolumn{3}{|l|}{ Marital relation } \\
\hline Consanguineous & 137 & 21.7 \\
\hline Nonconsanguineous & 493 & 78.3 \\
\hline \multicolumn{3}{|l|}{ Family type } \\
\hline Nuclear & 191 & 30.3 \\
\hline Joint & 439 & 69.7 \\
\hline \multicolumn{3}{|c|}{ Family monthly income (IRs) } \\
\hline$<3,000$ & 127 & 20.2 \\
\hline $3,000-10,000$ & 412 & 65.4 \\
\hline$>10,000$ & 91 & 4.4 \\
\hline \multicolumn{3}{|c|}{ Educational status of the husband } \\
\hline Illiterate & 56 & 8.9 \\
\hline Primary level & 139 & 22.1 \\
\hline Secondary level & 314 & 49.8 \\
\hline PUC & 74 & 11.7 \\
\hline University degree & 47 & 7.5 \\
\hline \multicolumn{3}{|c|}{ Occupation of the husband } \\
\hline Unemployed & 3 & 0.5 \\
\hline Farming & 88 & 14.0 \\
\hline Government service & 37 & 5.9 \\
\hline Private service & 110 & 17.5 \\
\hline Business & 90 & 14.3 \\
\hline Labor & 287 & 45.6 \\
\hline Other & 15 & 2.4 \\
\hline
\end{tabular}

$\mathrm{SD}=$ Standard deviation, $\mathrm{PUC}=$ pre-university college, $\mathrm{IRs}=$ Indian rupees

do so than those who were less aware. Moreover, family monthly income proved to be other most significant contributing factor of PNC service utilization. Women who had high family monthly income were 2.08 times (95\% CI: 1.18-3.65) more likely $(P=0.01)$ to have obtained postnatal care (PNC) service than women with low income. It is interesting to note that the study also showed the women whose husband perform the farming or labor work were 1.84 times (95\% CI: $1.247-2.710, P=0.002)$ more likely to use the service than those who were government or private officials or business person. Type and size of the family also contributed the important role for utilizing of the PNC service. The study revealed that the women who were from joint family were 1.54 times $(95 \%$ CI: 1.247-2.710) more likely $(P=0.03)$ to use the service than the women from nuclear family. Similarly mothers who were from large family were 2.017 times (95\% CI: 1.089-3.739) more likely ( $P=$ $0.02)$ to use the services than mother who were from small family.

The study also proved that place of the delivery, age of mother at first pregnancy, and ANC service utility practices played further more significant role on PNC utilization. Women who used institutional delivery services were 2.42 times (95\% CI: 1.24-4.74) more likely $(P=0.008)$ to use the PNC service than the women who delivered in home. Similarly, women who were first pregnant in their normal age (20-34 years) were 1.554 times (95\% CI: 1.020-2.369) more likely $(P=0.03)$ to use the PNC service than the women who were got their first pregnancy in teenage or 35 years and more. In addition, women who used the ANC service during their pregnancy time were 2.27 times (95\% CI: 1.08-4.75) more likely $(P<0.02)$ to use the PNC service than those who did not used so [Table 3].

\section{DISCUSSION}

According to World Health Organization (WHO), at least three home visit by health workers, continuation of IFA tablet intake by 42 days of delivery, caring of infection, management of postpartum hemorrhage, getting breast feeding education, caring of breast and nipple, postpartum exercise, getting nutrition education, maintaining proper nutrition and advice of choosing suitable family planning devices are the basic services require to the mother during the postnatal period. This study shows that nearly four-fifth of the mothers used postnatal service properly which was more than other study finding in Nepal, India and Bangladesh. ${ }^{[9,10]}$ Our study showed that about $89.0 \%$ took IFA tablet during postnatal period. This was a good achievement of postnatal service utility. This could be due to the reason that most of the mother were delivered in institution and home visit of health worker after delivery. More than three-fifth of the participants met with nurse/health workers at least three times during postnatal period. It was found that, only one quarter of the postnatal mother took vitamin A capsule which was lesser than the study reported from Nepal. ${ }^{[10]}$ The difference was due to the reason that in Nepal, the government launched the vitamin A program as national program and made mandatory, but in India it is not mandatory. The common health problems perceived by women during the postnatal and later period were puerperal sepsis with fever $(35.1 \%)$, followed by uterus prolapsed with backache and abdominal pain $(27.1 \%)$, weakness $(14.4 \%)$, mastitis $(10.6 \%)$, vaginal bleeding with pain (7.4\%), and lower abdominal pain (5.3\%) which is 


\begin{tabular}{|c|c|c|}
\hline Service utilization & Frequency & Percentage \\
\hline \multicolumn{3}{|l|}{ Intake of IFA tablet by 42 days of delivery } \\
\hline Yes & 561 & 89.0 \\
\hline No & 69 & 11.0 \\
\hline \multicolumn{3}{|l|}{ Intake of vitamin A capsule } \\
\hline Yes & 159 & 25.2 \\
\hline No & 471 & 74.8 \\
\hline \multicolumn{3}{|l|}{ Visited by nurses } \\
\hline Yes & 569 & 90.3 \\
\hline No & 61 & 9.7 \\
\hline \multicolumn{3}{|l|}{ Frequency of visiting by nurses } \\
\hline $1-2$ times & 220 & 38.7 \\
\hline$\geq 3$ times & 349 & 61.3 \\
\hline \multicolumn{3}{|l|}{ Got advice on caring of breast and nipple } \\
\hline Yes & 502 & 79.7 \\
\hline No & 128 & 20.3 \\
\hline \multicolumn{3}{|l|}{ Got advice related to art of breast feeding } \\
\hline Yes & 583 & 92.5 \\
\hline No & 47 & 7.5 \\
\hline \multicolumn{3}{|l|}{ Got advice on postnatal exercise } \\
\hline Yes & 428 & 67.9 \\
\hline No & 202 & 32.1 \\
\hline \multicolumn{3}{|l|}{ Got nutrition education } \\
\hline Yes & 561 & 89.0 \\
\hline No & 69 & 11.0 \\
\hline \multicolumn{3}{|l|}{ Got family planning education } \\
\hline Yes & 452 & 71.7 \\
\hline No & 178 & 28.3 \\
\hline \multicolumn{3}{|l|}{ Used of contraceptive after delivery } \\
\hline Yes & 204 & 32.4 \\
\hline No & 426 & 67.6 \\
\hline \multicolumn{3}{|l|}{ Types of contraceptive device used $(n=204)$} \\
\hline Vasectomy & 33 & 16.2 \\
\hline Laproscopy/Minilap/Tubectomi & 76 & 37.3 \\
\hline Condom & 64 & 31.4 \\
\hline Oral pills & 7 & 3.4 \\
\hline Depo-Provera & 4 & 2.0 \\
\hline Intrauterine device & 20 & 9.8 \\
\hline \multicolumn{3}{|l|}{ Suffering by health problems during postnatal period $(n=630)$} \\
\hline Yes & 188 & 29.8 \\
\hline No & 442 & 70.2 \\
\hline \multicolumn{3}{|l|}{ Health problem during postnatal period $(n=188)$} \\
\hline Puerperal sepsis with fever and abdominal pain & 66 & 35.1 \\
\hline Uterus prolapsed with abdominal pain and backache & 51 & 27.1 \\
\hline Weakness & 27 & 14.4 \\
\hline Mastitis & 20 & 10.6 \\
\hline Vaginal pain and bleeding & 14 & 7.4 \\
\hline Lower abdominal pain only & 10 & 5.3 \\
\hline \multicolumn{3}{|l|}{ Got advice related to uterus prolapsed from the health worker } \\
\hline Yes & 535 & 84.9 \\
\hline No & 95 & 15.1 \\
\hline \multicolumn{3}{|c|}{ Management of health problem during post natal Period $(n=188)$} \\
\hline Took medicine with advice of ANM & 88 & 46.8 \\
\hline Treated in hospital/clinic & 46 & 24.5 \\
\hline Home treatment & 31 & 16.4 \\
\hline No treatment & 23 & 12.3 \\
\hline
\end{tabular}

IFA = Iron and folic acid, ANM = auxiliary nurse midwife 


\begin{tabular}{|c|c|c|c|c|c|c|c|}
\hline \multirow[t]{2}{*}{ Variables } & & \multicolumn{2}{|c|}{ PNC service use } & \multirow{2}{*}{$\begin{array}{l}\text { Chi-square } \\
\qquad\left(\chi^{2}\right)\end{array}$} & \multirow[t]{2}{*}{ OR } & \multirow[t]{2}{*}{$95 \% \mathrm{Cl}$} & \multirow[t]{2}{*}{$P$-value } \\
\hline & & Good $(n=498)$ & Poor $(n=132)$ & & & & \\
\hline \multirow[t]{2}{*}{ Age (in years) } & $20-35$ & $485(79.1)$ & $128(20.90)$ & 0.07 & 1.16 & $0.37-3.63$ & 0.791 \\
\hline & $\leq 19$ and $>35$ & $13(76.4)$ & $4(23.5)$ & & & & \\
\hline \multirow[t]{2}{*}{ Educational level } & Some schooling & $473(80.0)$ & $117(20.0)$ & 7.06 & 2.426 & $1.24-4.75$ & $0.008^{*}$ \\
\hline & No schooling & $25(65.0)$ & $15(35.0)$ & & & & \\
\hline \multirow[t]{2}{*}{ Religion } & Hindus & 290 (76.9) & $87(23.1)$ & 2.58 & 0.721 & $0.483-1.077$ & 0.110 \\
\hline & Others & $208(82.2)$ & $45(17.8)$ & & & & \\
\hline \multirow[t]{2}{*}{ Occupation of mother } & Housewife & $448(79.2)$ & $118(20.8)$ & 0.037 & 1.063 & $0.568-1.989$ & 0.848 \\
\hline & Others & $50(78.1)$ & $14(2.9)$ & & & & \\
\hline \multirow{2}{*}{$\begin{array}{l}\text { Monthly family } \\
\text { income (in IRs) }\end{array}$} & $<3,000$ & $111(87.4)$ & $16(12.6)$ & 6.70 & 2.08 & $1.18-3.65$ & $0.01^{* *}$ \\
\hline & $\geq 3,000$ & 387 (76.9) & $116(23.10$ & & & & \\
\hline \multirow[t]{2}{*}{ Types of family } & Joint & 357 (81.3) & $82(18.7)$ & 4.51 & 1.54 & $1.247-2.710$ & $0.03^{*}$ \\
\hline & Nuclear & $141(73.8)$ & $50(26.2)$ & & & & \\
\hline \multirow[t]{2}{*}{ Family size } & Large & $464(80.1)$ & 115 (19.9) & 5.136 & 2.017 & $1.089-3.739$ & $0.02^{*}$ \\
\hline & Small & $34(66.7)$ & $17(33.3)$ & & & & \\
\hline \multirow[t]{2}{*}{ Occupation of husband } & $\begin{array}{l}\text { Farming/labors } \\
\text { and others }\end{array}$ & $326(83.0)$ & $67(17.0)$ & 9.61 & 1.84 & $1.247-2.710$ & $0.002^{* *}$ \\
\hline & Service/business & $172(72.6)$ & $65(27.4)$ & & & & \\
\hline \multirow[t]{2}{*}{ Education of husband } & Some schooling & $454(79.1)$ & $120(20.9)$ & 0.008 & 1.032 & $0.528-2.015$ & 0.972 \\
\hline & No schooling & $44(78.6)$ & $12(21.4)$ & & & & \\
\hline \multirow[t]{2}{*}{ Level of awareness } & High & $460(80.7)$ & $110(19.3)$ & 9.89 & 2.421 & $1.376-4.259$ & $0.002^{* *}$ \\
\hline & Low & $38(63.3)$ & $22(33.7)$ & & & & \\
\hline \multirow[t]{2}{*}{ Distance (in km) } & $\leq 6$ & 267 (78.5) & $73(21.5)$ & 0.12 & 0.934 & $0.635-1.374$ & 0.729 \\
\hline & $>6$ & $231(99.7)$ & $599(20.3)$ & & & & \\
\hline \multirow[t]{2}{*}{ Cost of transportation (IRs) } & $\geq 40$ (inexpensive) & $339(80.1)$ & $84(19.9)$ & 0.931 & 1.218 & $0.815-1.820$ & 0.335 \\
\hline & $>40$ (expensive) & $159(76.8)$ & $48(23.2)$ & & & & \\
\hline \multirow[t]{2}{*}{ Gravidity } & $\geq 2$ & 315 (79.9) & $79(20.1)$ & 0.516 & 1.155 & $0.78-1.71$ & 0.472 \\
\hline & First & $183(77.5)$ & $53(22.5)$ & & & & \\
\hline \multirow[t]{2}{*}{ Parity } & $\geq 2$ (multi parity) & $303(80.8)$ & $72(19.2)$ & 1.718 & 1.295 & $0.879-1.907$ & 0.19 \\
\hline & First & $195(76.5)$ & $60(23.5)$ & & & & \\
\hline \multirow[t]{2}{*}{ History of neonatal deaths } & Yes & $27(96.4)$ & $1(3.6)$ & 5.345 & 7.51 & $1.01-55.78$ & $0.021^{*}$ \\
\hline & No & $471(78.2)$ & $131(21.8)$ & & & & \\
\hline \multirow[t]{2}{*}{ Place of delivery } & Institution & $473(80.2)$ & $117(9.8)$ & 7.062 & 2.426 & $1.24-4.74$ & $0.008^{* *}$ \\
\hline & Home & $25(62.5)$ & $15(37.5)$ & & & & \\
\hline \multirow{2}{*}{$\begin{array}{l}\text { Age of mother at first } \\
\text { pregnancy }\end{array}$} & Normal age & $383(8.0)$ & $90(19.0)$ & 4.246 & 1.554 & $1.02-2.369$ & $0.039^{*}$ \\
\hline & Risk age & $115(73.2)$ & $42(26.8)$ & & & & \\
\hline \multirow[t]{2}{*}{ ANC service use } & Yes & 477 (79.9) & $120(20.1)$ & 4.994 & 2.271 & $1.08-4.75$ & $0.025^{*}$ \\
\hline & No & $21(63.6)$ & $12(36.4)$ & & & & \\
\hline
\end{tabular}

*Siqnificant at $P<0.05, * *$ siqnificant at $P<0.01 . \mathrm{PNC}=$ Postnatal care, $\mathrm{OR}=$ odds ratio, $\mathrm{Cl}=$ confidence interval, IRs $=$ Indian rupees, $\mathrm{ANC}=$ antenatal care

somehow different from the study results from Nepal. ${ }^{[10]}$ The study conducted in Nepal showed that most of the mother suffered from weakness $(27 \%)$ followed by mastitis (27\%), vaginal bleeding $(20 \%)$, fever $(13 \%)$, vaginal pain (13\%), and a prolapsed uterus (7\%). It was found that education of the mother, family income, types and size of family, occupation of husband, level of knowledge on PNC, history of previous neonatal death, health service used by mothers during antenatal period, and place of delivery were significantly associated with PNC services use. This study showed that level of awareness $(\mathrm{OR}=9.89)$ and education of mother $(\mathrm{OR}=2.42)$ were strong predictors of for PNC service use which were in line with the study conducted in other parts of India and abroad. ${ }^{[9,11-13]}$ Similarly, monthly family income, occupation of husband, and place of delivery were other most important determinants of PNC service utilization. Mothers who had monthly family income $<3,000$ IRs were more likely to use the PNC service than those who have $\geq 3,000$ IRs. This is due to the good impact of NRHM and other $\mathrm{MCH}$ program conducted by government and other organization with focusing to the people of below poverty line. This finding was somehow in contrast with the study findings in Bangalore, India. ${ }^{[1]}$ Similarly, women whose husband were farmers or labor, took the PNC service 9.6 times more than the other whose husband were service holder and business man. This could be due to the reason that farming and laboring are the free autonomous jobs and they can give time more, while service holder and business person could not manage time for supporting. This finding was matched with the study report of Srivastava et al. ${ }^{[9]}$ Our study revealed that mothers who delivered in hospital or PHC used more PNC service than the mother who delivered at home $(\mathrm{OR}=7.062)$ which is in line with the others similar study. ${ }^{[14]}$ Utilization of antenatal and delivery care 
services has positive impact on the use of PNC which is in line with other study. ${ }^{[12,13]}$ There was no association found with variables like teenage pregnancy, type of family, high risk pregnancy, occupation of mother, parity, gravidity, and education of husband; like the finding of the study in Bangalore. ${ }^{[11]}$

\section{CONCLUSION}

More than three quarters of mothers had used the proper postnatal maternity services. Education of mother, monthly family income, awareness on postnatal service use and its benefits, types and size of family, antenatal service used, and delivery place were found as significant contributing factors for postnatal service utilization in rural Belgaum. Advancement of health facilities, encouragement of service provider, sustainable maternal, and child health programs and creating awareness will support to achieve furthermore better results.

\section{ACKNOWLEDGEMENT}

The study team wants to put the sincere gratitude to KLE University ICDS offices Belgaum for technical support and UGC, Nepal, for financial support. Moreover, Primary Healthcare Centers of rural Belgaum, Aaganwadi workers, and all participants were thankful for supporting during data collection.

\section{REFERENCES}

1. Worldwide statistics 2011. Available from: http://www.google.com [Last cited on 2012 Mar 26].

2. UNFPA. The State of the World's Midwifery: Delivering Health, Saving Lives; 2011.

3. Policy project. Maternal and Neonatal Program Index (MNPI): A tool for maternal health advocates. Published Project Report: Maternal Health and Child Study; 1999.

4. Ashford L. Hidden Suffering: disabilities from pregnancy and childbirth in less developed countries. Population Reference Bureau, 2004:1-6. Available from: http://www.prb.org/Template.cfm?Section=PRB\&template=/ ContentManagement/Content Display.cfm\&ContentID=6658 [Last cited on 2012 June 23].

5. World Health Organization. Making pregnancy safer: why is this issue important? 2004. Available from: http://www.who. milleniumgoalsformaternalhealth.htm [Last cited on 2013 Apr 28].

6. World Health Organization (WHO). Health for all. Series No. 1. Geneva: World Health Organization (WHO); 1978.

7. Kumar S. Challenges of maternal mortality reduction and opportunities under national rural health mission--a critical appraisal. Indian J Public Health 2005;49:163-7.

8. World Health Organization. Accelerating progress towards achieving maternal and child health Millennium Development Goals (MDGs) 4 and 5 in South-East Asia: Report to high-level consultation; 2009.

9. Srivastava RK, Kansal S. Assessment of Utilization of RCH Services and Client Satisfaction under Different Level of Health Facilities in Varanasi District. UNFPA published report 2005.

10. Dhakal S, Chapman GN, Simkhada PP, van Teijlingen ER, Stephens J, Raja AE. Utilization of postnatal care among rural women in Nepal. BMC Pregnancy Childbirth 2007;7:19.

11. Ranganath TS, Poornima CA. Study on utilization of maternal services in urban slums of Bangalore. Int J Basic Appl Med Sci 2011;1:70-5.

12. Chimankar DA, Sahoo H. Factors influencing the utilization of maternal health care services in Uttarakhand. J Ethno Med 2011;5:209-16.

13. Rahman MM, Haque SE, Zahan MS. Factors affecting the utilization of postpartum care among young mothers in Bangladesh. Health Soc Care Community 2011;9:138-47.

14. Srivastava RK, Kansal S, Tiwari VK, Piang L, Chand R, Nandan D. Assessment of utilization of $\mathrm{RCH}$ services and client satisfaction at different level of health facilities in Varanasi District. Indian J Public Health 2009;53:183-9.

How to cite this article: Paudel DP, Nilgar B, Bhandankar M. Determinants of postnatal maternity care service utilization in rural Belgaum of Karnataka, India: A community based cross-sectional study. Int J Med Public Health 2014;4:96-101.

Source of Support: KLE University and UGC Nepal, Conflict of Interest: None declared. 